\title{
Article
}

\section{Interpersonal violence and abuse in young people's relationships in five European countries: online and offline normalisation of heteronormativity}

Aghtaie, Nadia, Larkins, Cath, Barter, Christine Anne, Stanley, Nicky, Wood, Marsha and Øverlien, Carolina

Available at http://clok.uclan.ac.uk/28015/

Aghtaie, Nadia, Larkins, Cath ORCID: 0000-0003-2999-6916, Barter, Christine Anne ORCID: 0000-0001-5682-5333, Stanley, Nicky ORCID: 0000-0002-76441625, Wood, Marsha and Øverlien, Carolina (2018) Interpersonal violence and abuse in young people's relationships in five European countries: online and offline normalisation of heteronormativity. Journal of Gender-Based Violence, 2 (2). pp. 293-310. ISSN 2398-6808

It is advisable to refer to the publisher's version if you intend to cite from the work. http://dx.doi.org/10.1332/239868018X15263879270302

For more information about UCLan's research in this area go to http://www.uclan.ac.uk/researchgroups/ and search for <name of research Group>.

For information about Research generally at UCLan please go to http://www.uclan.ac.uk/research/

All outputs in CLoK are protected by Intellectual Property Rights law, including Copyright law. Copyright, IPR and Moral Rights for the works on this site are retained by the individual authors and/or other copyright owners. Terms and conditions for use of this material are defined in the policies page. 
Aghtaie, N., Barter, C., Stanley, N., Wood, M. J. E., \& Överlien, C. (2018). Interpersonal violence and abuse in young people's relationships in five European countries: online and offline normalisation of heteronormativity. Journal of Gender-Based Violence, 2(2), 293-310.

https://doi.org/10.1332/239868018X15263879270302

Peer reviewed version

Link to published version (if available):

$10.1332 / 239868018 X 15263879270302$

This is the author accepted manuscript (AAM). The final published version (version of record) is available online via Policy Press at https://www.ingentaconnect.com/contentone/tpp/jgbv/2018/00000002/00000002/art00003 .

Please refer to any applicable terms of use of the publisher. 


\section{Journal of Gender-Based Violence \\ Interpersonal violence and abuse in young people's relationships in five European countries: online and offline normalisation of heteronormativity \\ --Manuscript Draft--}

\begin{tabular}{|c|c|}
\hline Manuscript Number: & JGBV-D-17-00022R2 \\
\hline Article Type: & Academic article \\
\hline Full Title: & $\begin{array}{l}\text { Interpersonal violence and abuse in young people's relationships in five European } \\
\text { countries: online and offline normalisation of heteronormativity }\end{array}$ \\
\hline First Author: & Nadia Aghtaie, PhD \\
\hline Corresponding Author: & $\begin{array}{l}\text { Nadia Aghtaie, PhD } \\
\text { University of Bristol } \\
\text { Bristol, UNITED KINGDOM }\end{array}$ \\
\hline \multicolumn{2}{|l|}{$\begin{array}{l}\text { Corresponding Author Secondary } \\
\text { Information: }\end{array}$} \\
\hline Corresponding Author E-Mail: & nadia.aghtaie@bristol.ac.uk \\
\hline \multirow[t]{5}{*}{ Other Authors: } & cath Larkins \\
\hline & Christine Barter \\
\hline & Nicky Stanley \\
\hline & Marsh Wood \\
\hline & Carolina Øverlien \\
\hline Abstract: & $\begin{array}{l}\text { Qualitative interviews with } 91 \text { young people aged } 13-18 \text { in Bulgaria, Cyprus, England, } \\
\text { Italy and Norway explored their experiences of intimate partner violence and abuse } \\
\text { (IPVA). Some young women experienced extensive offline sexual pressure and young } \\
\text { women were substantially more negatively affected by IPVA than young men. The data } \\
\text { revealed that online space has created new mechanisms of control and surveillance } \\
\text { that can intensify the impact of offline abuse. Analysing the data in the light of existing } \\
\text { theories of cultural violence and coercive control, we explore both the normalising } \\
\text { influence of prevailing heteronormative models of femininity and masculinity as well as } \\
\text { young people's agency to resist such normalisation. }\end{array}$ \\
\hline Keywords: & $\begin{array}{l}\text { young people, intimate partner violence, heteronormativity, cultural violence, online } \\
\text { violence. }\end{array}$ \\
\hline \multicolumn{2}{|l|}{ Additional Information: } \\
\hline Question & Response \\
\hline $\begin{array}{l}\text { Key Messages } \\
\text { Please enter } 2-3 \text { single sentence bullet } \\
\text { points describing the key messages of the } \\
\text { paper. }\end{array}$ & $\begin{array}{l}\text { 1. Sometimes young people who experience and perpetrate IPVA understand this as } \\
\text { normal gendered behaviour } \\
\text { 2. the normalisation of abuse is further perpetuated when young people equate control } \\
\text { to love, care and protection } \\
\text { 3.Online space provides new patriarchal platforms for the extending the scope and } \\
\text { regularity of monitoring and emotional abuse }\end{array}$ \\
\hline $\begin{array}{l}\text { Word Count } \\
\text { Academic articles should be between } \\
5000 \text { and } 7000 \text { words in length. } \\
\text { Policy and Practice articles should be } \\
\text { between } 2000 \text { and } 4000 \text { words in length. } \\
\text { Open Space pieces should be between } \\
\text { should be between } 2000 \text { and } 4000 \text { words } \\
\text { in length. }\end{array}$ & 7520 \\
\hline
\end{tabular}




\begin{tabular}{|c|c|c|}
\hline \multicolumn{3}{|l|}{$\begin{array}{l}\text { Special issue } \\
\text { Is this a submission for a special issue? If } \\
\text { so please give details of the special issue, } \\
\text { including the Editor if known. }\end{array}$} \\
\hline Funding Information: & Daphne & Christine Barter \\
\hline \multicolumn{3}{|l|}{ Manuscript Region of Origin: } \\
\hline \multicolumn{3}{|l|}{ Author Comments: } \\
\hline Response to Reviewers: & \multicolumn{2}{|c|}{$\begin{array}{l}\text { This has already been submitted. I am now intending to upload my non-anonymised } \\
\text { final version }\end{array}$} \\
\hline
\end{tabular}




\section{Background}

Gender-based physical, sexual and emotional violence is a global concern (WHO, 2014).

Most of the studies on intimate partner violence and abuse (IPVA) in young people's relationships have been carried out using surveys in the United States (Schnurr et al 2010; Ali et al 2011; Maas et al 2010). Prevalence data indicates that psychological violence may be the most common form of abuse followed by moderate to severe forms of physical violence and sexual abuse (Foshee et al, 2009; Foshee \& Matthew, 2007). Protective factors for IPVA victimisation appear to include bonding to parents and social skills (Mass et al 2010); risk factors include experience of physical abuse from a parent and alcohol use (Scnurr et al.2010). Across these studies (Schnurr et al 2010; Ali et al 2011) there appears to be significant variation in how young people perceive violence, including violence between boys and girls, in terms of both perpetration and victimisation. Whilst IPVA or 'teen dating violence' is increasingly acknowledged in the US, in Europe recognition and research is currently developing. A small body of European research (Barter, 2009; Fox, 2014) reveals similar levels of prevalence, and a few studies have addressed the complexity of abuse in young people's relationships using in-depth interviews to increase understandings of young people's experiences (Barter et al 2009; Wood et al, 2010; Wood \& Barter, 2015) There is a paucity of research exploring the interconnectedness of online and offline abuse across Europe. The British Home Office (2013) recently broadened their definition of domestic abuse to include young people between the ages of 16 and 18 and to include the concept of coercive control, which derives from Stark's work (Stark 2007). Including younger teenagers (Fox et al, 2014) and the concept of coercive control have been important shifts that addresses the limitations of focusing on incident- based violence (Aghtaie \& Gangoli, 2015). However, young people below the age of 16 may also experience IPVA and definitions that 


\section{Theoretical framework}

Aghtaie's (2016 \& 2017) theoretical model uses the concepts of 'cultural violence' first introduced by Galtung (1990) to demonstrate how coercive control and violence can be normalised within a society. Galtung defines cultural violence as:

'The symbolic sphere of our existence exemplified by cultural features such as religion and ideology, language and art, empirical science and formal science... 
Cultural violence makes direct and structural violence look, even feel, right—or at least not wrong ... cultural violence highlights the way in which the act of direct violence and the fact of structural violence are legitimized and thus rendered acceptable in society'(Galtung, 1990:291).

Here we adopt the Aghtaie's (2016\& 2017) theoretical framework and expand Galtung's approach to include gender as a social hierarchy in which cultural features, such as heteronormative beliefs and notions of ideal manhood and womanhood, position masculinity as superior to femininity. Cultural violence serves to justify and normalise young men's sexual pressure, control and coercion as 'natural'. As Wood (2001) suggests, men are perceived as dominant and domineering and women as subordinate and in need of protection.

This model appears to be confirmed by existing research with young people. Male power and aggression can be normalised amongst young people as a result of the dominant patriarchal culture (Fineran and Bennett 1999; Tolman et al. 2003; Lombard, 2014) with young men's sexually aggressive behaviour understood as merely 'boys being boys' (Connell 1987; Messerschmidt 2012). This context may affect young people's reporting of various experiences of violence and abuse with young people less likely to identify and report behaviour as abusive when wider cultural norms support and reinforce such behaviour. Hierarchical gender expectations often accompany attitudes that tolerate violent behaviours in young people's relationships (Licher \& McCloskey, 2014). A key question in our analysis, therefore, is: Do young people who experience and perpetrate IPVA understand this as normal gendered behaviour?

Stark (2007) argues that, within the Western context, masculinity is mostly associated with 'being in control'. Universal masculinity is equated to rationality, reasonableness and righteousness as opposed to female irrationality, emotionality and immorality. He employs 
the concept of coercive control to demonstrate how men use different tactics to exert power over women. He argues that coercive control aims to '... usurp and master a partner's subjectivity... and its focus on imposing sex stereotypes in everyday life. The result is a condition of unfreedom... that is "gendered" in its construction, delivery and consequence' (ibid: 205).

Barter et al (2009)found that Stark's (2007) understanding of coercive control resonated with young people's (13-16 years old) accounts of their experiences. Aggression, controlling behaviours and sexual coercion are sometimes interpreted by young people within narratives of romance, love and caring (Wood, 2001; Wood et al, 2010; Barter, 2009). Although there is a focus on control in young people's experience of IPVA, current heteronormative beliefs also endorse men's lack of control of their aggression and sexuality whilst women are positioned as responsive passive beings. Young women are perceived as responsible for their male counterparts' intractable behaviours. Their role as 'sexual gate keepers'(Powell, 2007; Eaton \& Matamala, 2014), whose responsibility is to please boys, is sustained through normalisation of a heteronormative model in which initiating and engaging in various degrees of sexual activity is expected. A second question for our analysis, therefore, is: Do young people experiencing IPVA associate this with narratives of male's 'reasonableness' and 'being in control' or with accounts of young men's out-of-control behaviour which is in return often linked to young women's 'need to please' and self-blame?

Finally, there are concerns that culture impacts on young people's intimate relationships (see Burman \& Cartmel, 2005; Barter et al, 2009; Nocentini et al, 2010; Fox et al, 2014) including through digital technologies (Drauker and Martsloff 2010), Given the increased internet usage by young people (Livingstone et al, 2011), offline cultural features such as presumed female submissiveness, that reproduce gender as binary and natural, rather than socially constructed (West and Zimmerman, 1997) are echoed in restrictive expressions of genders 


\section{Methodology:}

A total of 100 in-depth semi-structured interviews were conducted with young people across five different countries: Bulgaria, Cyprus, England, Italy and Norway. These countries were selected to provide a wide geographical spread and diversity in their levels of gender equality (see European Institute for Gender Equality, 2013) as well as variations in young people's use of new technologies (Livingstone et al, 2011). It was a purposive sample selected to include young people with experience of IPVA in their own relationships. Young people were recruited through schools' pastoral services, and from settings such as youth camps, workshops for young people and specialist services including those working with IPVA. 
Overall, 91 of the 100 interviewees shared personal experience of control, surveillance,

An interview schedule and vignettes were used to gather data. While these research instruments were consistent across countries, guidance was received from young people's advisory groups in each country, to ensure that they were appropriate in both content and wording when translated from English. The interview schedule contained a list of themes and possible sub-questions addressing the topics of relationships, control and surveillance, sexting and sexual pressure, experiences of different forms of violence, impact, protective and risk factors as well as conceptual issues such as gender expectations. Sometimes vignettes were used at the beginning to facilitate the discussion and to put young participants at ease, if it was deemed necessary. All interviews were one-to-one and took place in private rooms in the organisations that introduced young people to the research team. The interviews lasted from 
40 minutes to an hour and half. Afterwards, young people were thanked for their help, were given a voucher worth $€ 10$ and were directed to relevant sources of support.

Framework analysis (Ritchie et al, 2003: 219) which is a 'matrix based method for ordering and synthesizing data' was used to analyse the data to ensure that comparable issues were identified and understood in context. A thematic framework is the central component of the method. An inductive approach (Braun and Clarke, 2006) was adopted to identify the codes based on extracts of transcripts relating to the research questions. Following familiarization and refining through raw data and cross-sectional labelling, the main themes were identified as: control and surveillance; physical and emotional violence; and sexting and sexual coercion. These were divided into a series of related subtopics. Each main theme was 'charted' in its own matrix with every respondent assigned a row and each column designated to a subtopic. Within each of these we identified the interplay of heteronormative cultural acceptance, normalisation and narratives of masculinity and the use of digital technologies such as Facebook, Snapchat, and Instagram. This process enabled us to explore and understand how and in which contexts, normalised patterns of IPVA are repeated or resisted by some individuals.

\section{Participant characteristics}

Recruiting participants was challenging in all five countries and reliance on others to gatekeep access to interviewees meant that researchers had little control over the diversity of the sample. Sometimes difficulties in recruiting were due to the fact that support services were either not available or scarce; schools might not be prepared to 'open a can of worms', as stated by one school's principal in Norway who considered that the school lacked sufficient resources to offer young people the support they might need. 
All ninety-one interviewees described experiencing or perpetrating control and surveillance, sexual pressure and coercion, and physical and emotional abuse. Control and surveillance was the most prevalent form of abuse, and had been experienced by almost all of the female interviewees. A few young men described only perpetrating control but not being on the receiving end and a very small number of young men from Norway described only being victims.

Usually, these forms of control and surveillance were uni-directional; young women particularly those from Italy, England and Norway, tended to describe experiencing control and surveillance from male partners,:

...There were times when he would just grab my phone from my hands and wouldn't let go of it, so he would check my messages (Tatiana, female 16, Cyprus).

Nearly two-thirds described experiencing behaviours which could be deemed emotionally abusive (deceit; derogatory comments; being humiliated; betraying privacy; violent outbursts and extremes of rejection followed by devotion). No interviewees described perpetrating sexual coercion, but more than half of female participants described experiencing some form 
IPVA takes both online and offline forms. Methods of online control included: being instructed not to chat with specific people or to delete contacts; being pressured or forced to give account passwords; having text conversations monitored or receiving constant phone calls and text messages to check on their whereabouts. Offline control included: having contact with friends limited by their partner; being told what to wear; experiencing partners turning up uninvited; and being confronted by their partner's anger if they wanted to take part in activities without them. Notably, there were relatively few accounts of online only control and surveillance and none at all in Cyprus and Norway. Rather, as Iacovos and Smaragda describe below, there appeared to be a melding of online and offline controlling behaviour and surveillance regardless of whether partners were physically present or not.

We were at the computer together once and I noticed she was chatting with someone and I asked her, what's this all about and she told me (that some boy was talking to her) and I went crazy. And because I reacted, and she doesn't like it when I am like 
that, when I start picking fights with her [...] she stopped doing that (Iacovos, male17, Cyprus)

'He said 'no you will not go out with so and so', 'no you won't wear that dress', ... I felt that I am 16 and I felt married!... he would call that friend and check up on me or he would drive past to check that I was there,... then he asked me for my Facebook password, and he didn't let me speak to any of my friends. [...] he wanted to check if boys sent me messages.' (Smaragda, female 17, Cyprus)

It is interesting to note that within the Cyprian context, control within marriage was normalised by some participants.

Chiara stated that his ex-girlfriend used to slap him as a joke and he did not like it and hence he ended the relationship.

I told her to stop it, but she kept doing it [...] I got annoyed and ended the relationship(Chiara, male16, Italy)

Amy and Thea highlighted the omnipresence of the experience of digital monitoring:

He breathed down my neck 24/7, it was horrible (Amy, female15,UK)

He sort of took over my life. (Thea, female 15, Norway)

Emotional violence occurred on and offline, and most sexual coercion reported occurred offline, especially in Bulgaria and Cyprus. In both cases, digital sharing of images intensified the impact.

For example, Emma described her 16 year old boyfriend putting pressure on her to have phone sex when she was 14: 
we used to speak on the phone almost every night, it, at first it was really lighthearted conversations, ... then he started asking me questions like have you ever had phone sex? And it just got a bit like heavy... (Emma, female15, England)

Emma then described how her boyfriend forced her into sex with his friend and then shared this on Facebook.

\begin{abstract}
...He just made me do stuff with his friend ... there was a [post on Facebook] about his friend taking a picture of something that happened. ..., he led me to a park and started like pushing me around and forcing me to do things I didn't want to do and, and he pushed my head down so hard. I was sick everywhere and then they just left me (Emma, female15, England).
\end{abstract}

According to the UK Sexual Offence Act 2003, this sits within the legal definition of 'no consent'. However, Emma did not report the incident to the police and did not wish to elaborate on the above experience.

The data suggests that in both online and offline environments, there were some similarities in the areas in which partners exerted control, surveillance, and violence. However, online environments also enabled new forms of intrusion on space, tighter monitoring of actions and increased opportunities to move from private to public emotional abuse. The dissolved boundaries between on and offline environments has been highlighted in other research (Tompson and Cupples 2008) that provides accounts of partners turning up online in the password protected environments of young people's own social media accounts, just as they might turn up uninvited offline. These online accounts might be conceived of as more private than social gatherings with friends in physical public spaces (Wyness 2014). However, in these online environments, there are digital representations, such as friendship statuses, which can give controlling partners very clear indications of whether their instructions have been 


\section{Cultural violence: normalisation of IPVA through heteronormative beliefs?}

Initially, when asked directly, the majority of interviewees (two thirds) did not think that their experience of IPVA was a 'normal' part of being in a relationship:

'abuse should not be part of a relationship. It should be full of trust and not hurting each other, there should be happiness. '(Lauren, female14, England).

However, although, Lauren had a good understanding of what a healthy relationship should look like, when she was slapped by her boyfriend for not wanting to go out with him and his friend, she played it down, and believed to preserve harmony, she would 'need to please' him by being more invested in the relationship .

A significant minority (one in five) did understand their experience as 'normal':

'it's normal [for him to check on you] It shows interest' (Lito, female 17, Cyprus)

Normalisation of IPVA was particularly prevalent amongst young men from Bulgaria and in Cyprus, where almost all participants accepted this as a 'normal' part of relationships:

'Asking friends about what your partner was doing without you and checking each other's online communication is normal for a relationship. In this way, you can be certain that your partner does not lie to you. This makes the relationship stronger' (Krista, male18, Bulgaria)

The extent to which IPVA was normalised appeared to relate to gendered attitudes about differences between boys and girls. Krista explained that 'In most cases, the boy is expected 
to lead and make decisions, but sometimes he also has to listen to what the girl says'. And young people in Cyprus noted social expectations that men should be like 'hunters' whereas girls should be like 'Barbie' and 'submissive'. These expectations were reflected in essentialised differences between boys and girls. This cultural construction of femininity and masculinity legitimised the use of power and control which sometimes led to normalisation and justification of coercive control and sexual pressure. For example, in both Cyprus and Bulgaria, girls were considered to be 'more mature', 'innocent' and 'sensitive' than boys who tend to 'need more freedom' and be more focused on sex. Surveillance was particularly normalised within marriage:

'when the time comes [to marry] and I want to have a family ... then yes, there, up to a point, I will tell him where I am going, I will give him my password, he will (look at my mobile), because we will spend the rest of our lives together' (Voulla, female 18, Cyprus).

In all countries, there were examples of beliefs in polarised gender binaries ('girls are more sensitive' and 'boys need to be tough') and some interviewees had previously normalised their experience drawing on gendered binaries in which difference meant dominance, but no longer held these beliefs at the time of the interview, as Serena explains:

\section{My partner used to think that girls are weaker physically and psychologically, they need to be protected. I used to think the same but after we broke I learned that this is not at all true...(Serena, female 17, Italy)}

Further, the extent to which gendered binaries were employed to normalise IPVA varied according to the form of abuse and whether it was unidirectional or not. Interviewees who experienced sexual coercion and those who both perpetrated and were on the receiving end of online and offline control and surveillance tended to see these behaviours as 'normal'. Some 
young women, all from England and Norway, also described sexual pressure from peers or cultural expectations to have sex and again saw this as a cultural norm. Here Pernilla's and Jade's decision to whether engage in sexual activity or not is constrained by impilict pressures. Hence the line between force and choice becomes blurred:

'When you are going out with someone when you are 15, you have sex' (Pernille, female 16 Norway)

Friends would say that if I was him I would not be going out with you because you are taking so long... (Jade, female 16, England).

Sexual coercion in the form of persistent interpersonal pressure was seen as a gendered expectation by Lito who noted that society expected women to be 'proper' and 'decent' and exhibit good behaviour. In contrast, a boy who parties a lot and is seen with many girls was considered a 'stud', a 'macho man' and will be praised for his masculinity. Within this framework, the heteronormative view of men as active and women as passive receptacles for male sexual gratification acts to perpetuate male domination over women's bodies. This description of expected feminine purity and endorsed male desire reflects the gender binaries that can be conceptualised as cultural violence. Within the Cypriot context, virginity was described as a young woman's 'only dowry'; young women described being pressurised to remain virgins and this emerged as a key source of women's subordination:

...For a girl, this is not an easy thing. Her whole world will change because she will give the most valuable things she has (her virginity). I don't know how to say it. It is her only dowry, the dowry that she can decide to whom to give it to, but for a boy it's just so easy...(Elena, female 18, Cyprus).

Previous research has noted that Cyprian girls' sexual activity is under scrutiny and sometimes in the local peer culture, girls are placed on a fabricated and culturally 
widespread "virgin-whore" continuum (Skapoulli, 2009: 85). Social and cultural discourses of appropriate femininity and masculinity demand that young women remain virgin, which in return leads to control over female sexuality.

Heteronormative beliefs were also evident at times in relation to physical and emotional violence, as these accounts of physical and emotional violence demonstrate:

'The boy should be the boss, the girl should do everything that he asks. But he should treat her well... I said to her: Let's go to dance! I was a bit drunk. She did not want to. I took her out and started beating her'. (Peter, male18, Bulgaria)

'Yes there are times when I take out [my anger] on her unintentionally and she tells me not to. To calm down [.. ] I take out my anger on her because I am stressed every day...every day I have nerves'. (Iacovos, male 16, Cyprus)

Peter presents this gendered hierarchy as natural and Iacovos' partner is described as calming him down, fulfilling her feminine role.

In some cases, IPVA appeared to be reinforced by the peer culture that positions exploitation as 'normal' by displaying support for the perpetrator and blaming the victim. Below, Tone's account of comments on a picture describes a 'new' digital platform being used in combination with 'old' narratives of heteronormativity and dominant masculinities to produce and reproduce cultural violence:

'He began to talk dirty to me, calling me nasty things, like 'go to the kitchen, whore', but I didn't do as he wanted, I am not a slave. ... [He posted an old picture saying that his girlfriend was unfaithful to him with a girl] and then he kept writing these nasty comments, and people started commenting ...really horrible stuff (Tone, female 17, Norway) 


\title{
Masculinity as 'reasonableness', 'caring/love' and 'being in control'?
}

\begin{abstract}
The heteronormative beliefs described above were interwoven with narratives of reasonableness, care and control in some young people's interpretations of IPVA. When controlling behaviour was justified within the online and offline worlds, this utilised a discourse of what was 'reasonable' as well as referring to male egotism and expectations of female obedience:
\end{abstract}
'To have your girlfriend 'like' photos of people she doesn't know isn't such a nice thing to see in Facebook [...] "when she does that it's as if she is saying she doesn't want me...I don't want another man to come anywhere near her...I tell her not to wear certain clothes...' (Chrysanthos male 16, Cyprus).

In contrast, young mendescribed control exerted by their girlfriends as unreasonable and tended to respond to single incidents of controlling behaviour by switching off their phones or ending the relationship. For example, Stefano was told by his girlfriend that she did not want him to hang around with a certain group of friends when his ex-girlfriend was there: 'I don't accept these things. There is no reason to. I left her immediately' (Stefano, male 16, Italy)

Sometimes male control and surveillance were justified as a sign of love and protection. This was more prevalent in Bulgaria, Cyprus and Italy. For example, Serena explained:

Initially I thought it was ok... I even kind of like it, you know... I thought it was a sign he really cared for me (Serena, female17, Italy) 
Serena's comment indicates how aggression, controlling behaviours and sexual coercion can be interpreted as masculine expressions of love and caring. Being told what to wear and not to wear was also interpreted as a sign of protection and hence reasonable

'...I can understand why he says that because he doesn't want me like, because some girls get like half naked...he just gets protective... he doesn't want like to lose me'. (Chloe, female 15, England).

Rather than narratives that described masculinity as 'being in control', accounts of young men's out-of-control behaviour and young women's self-blame appeared more prevalent. Dany (Female 18, Bulgaria), one of the interviewees who did not normalise abusive behaviour, said that abusive behaviour is 'common enough' as boys sometimes 'think with their penis, which is their main problem'. Gendered self-blame and submissive femininity was evident when young women saw themselves as partially responsible for young men's uncontrollable emotional outbursts. For example, Aysa described her boyfriend's behaviour as sometimes hysterically furious and uncontrollable. She reported being terrified but she attributed some responsibility for his behaviour to herself:

In a way, I have provoked him [by sometimes saying nasty things back to him], or at least I was not capable of helping him and calming him down. (Asya, female 18, Bulgaria)

Liam (male15, England), who described his own controlling behaviour, referred to his emotional and physical violence as 'play fighting'. He perceived his ex-partner as controlling, but he thought that his requests to have access to her Facebook password or forbidding her to talk to her ex-boyfriend, were reasonable. 
Some young people were unsure whether male control was appropriate. For example, Guila,

\section{Young people's agency}

While much of the data revealed pervasive normalisation of gendered hierarchies and acceptance of 'universal masculinity' as both controlling and impulsive, with feminine roles associated with self-blame, there were also identifiable moments when young people described challenging this culture. As Drauker and Martsloff (2010)have noted, familiarity with digital technologies provided opportunities for resistance. Young women and young men described digital technology enabling them to block their partners from social media spaces, to shut down Facebook pages, change their phone numbers and to report victimisation. Some young women used their familiarity with digital technology to be 'careful', that is, to avoid surveillance by hiding their traces online. Others, who were confident in their friends, were also able to recruit their peers into not mentioning their name on the internet and not opening or reading abusive posts. Attention to context and exploration 
of young people's use of available other resources (such as friends, families and supportive services) provides a means of understanding how both online and face-to face IPVA can be challenged.

The interaction between personal perspectives, and peer groups were significant in deciding when and how to challenge. Peers could act to confirm submission to abusive behaviour but they could also collectively challenge controlling behaviour, as Cristina noted:

some friends had told me not to [give him my Facebook password]... (Cristina, female 18 , Italy)

Young men tended to be much quicker to reject controlling or coercive behaviour as 'ridiculous' or 'not normal' when it was aimed at them, perhaps reflecting structural norms of male dominance. In contrast, young women tended to take some time to develop a growing confidence and agency to question submissive peer, familial and cultural norms, perhaps due to a lack of cultural norms around challenging abusive behaviours. But even where controlling behaviour was normalised, young women could hold different views on their experiences at different times. Here, Soulla explains how her boyfriend used to gets 'restless' when she went out without him or forced her to share her Facebook password with him:

... I liked it!... I said ok, 'this guy must be interested in me to do such a thing [jealous, coercive behaviour]... But [at other times] I said 'Ok, this guy is insecure and I don't like the way he's dealing with his insecurities...I just felt that something had to change, that it wasn't possible to continue in that way... (Soulla, female 16, Cyprus)

Although Soulla's account replicates heteronormative understandings of roles, first depicting coercive behaviour as positive attention and then finding reasonable explanations for emotional abuse, she nonetheless indicates the potential for shifts away from acceptance towards rejection over time and a dawning realisation that this may be abusive behaviour. 
The importance of family environments was underlined by the fact that many of those interviewed who experienced IPVA had also witnessed domestic violence in their family homes. In these contexts, emotional abuse and controlling behaviour could be actively normalised by parents:

When I told my mum that we were having some problems because of his jealousy she told me that this was in fact just a demonstration of his affection for me. (Cristina, female18, Italy)

Whilst some young people ended abusive relationships with the active support of parents who repeatedly told them to leave, the above highlights the crucial importance of the construction of masculinity and femininity in the family context that could at times normalise behaviours that endorse male domination and control. Eventually, it was her friend's advice to end the relationship that Cristina followed (for more detailed responses on prevention and intervention see Hellevik et al, 2015). The intersection of friendship and family cultures therefore appear key contextual factors which can potentially support young people's journeys towards challenging abusive behaviour.

The attitudes of workers and cultures in specialist and generic services for young people were also significant. Emma (female 15, England)had witnessed her mother's experience of domestic violence but they had both received specialist support which Emma saw as enabling her to reject heteronormative roles.

... I've realised what makes a good relationship ... speaking to people at X service’ Emma also highlighted that 'schools can be sexist without realising it '...boys make [sexist jokes] like about women belonging in the kitchen... we asked 'Sir if we can go and play on a football pitch', he was like 'Oh stop messing about girls'...they all laugh about [abusive relationships and] they say stuff like "If my bird didn't do what I tell her, I'd just smack her". 
However, Emma also suggested resistance to cultures that maintain gendered hierarchies and normalise violence can be enabled by institutional cultures that clearly oppose male dominance:

most domestic violence is because the man thinks that he's better than the woman and that he's dominant over her ..., I think a good thing to be would be to add, like for an hour in high school, stuff like this to the curriculum, and ... maybe people who hadn't heard it was wrong would [then] know it was wrong, and girls would be able to recognise it (Emma, female15, England).

Emma had not approached a teacher to report the sexual violence she had experienced because she would feel 'awkward' and 'embarrassed' feeling that 'there's not much they can do'. Although the extent to which schools can 'facilitate young people's resistance to dominant discourses about youth sexuality remains questionable' (Spencer et al 2008 p.353), our data suggested that some schools have been able respond to IPVA with supportive interventions. And in these instances, the role of a competent teacher or external expert had been important.

\section{Conclusion}

Our data suggests that in all five countries, online and offline control and surveillance was accepted as normal by many young people. Some young Cyprian women deemed control and surveillance as ordinary and acceptable if married. Normalisation of IPVA was particularly prevalent among young men from Bulgaria and in Cyprus, where almost all participants accepted this as a normal part of relationships. Justification of control and surveillance as a form of love and protection was also more prevalent in Bulgaria and Cyprus as well as Italy. 
Unlike the other four countries, female virginity and chastity emerged as an important factor in Cyprus. Verbal abuse was extensive and tolerated by many young people interviewed; physical violence was also normalised, especially when alcohol was involved. Offline sexual pressure was extensive for some young women in all five countries and was normalised to the extent that rape was sometimes not recognised. Some young women, all from England and Norway, expressed cultural expectation to have sex when in a relationship. Apart from Cyprus, young people in the other four countries had sent sexual images of themselves and in England in particular this was perceived as normal behaviour. In all five countries using social networking as a means of perpetrating abuse intensified the impact. However, impact varied according to gender with young women reporting substantially more harmful impact than young men.

Our data also indicates that sometimes the dominant culture of masculinity equates to righteousness and to 'being in control' which can provide an atmosphere of tolerance that normalises abusive behaviours. This embedded tolerance among some young people can be conceptualised as cultural violence in which direct violence, for example beating your girlfriend for not submitting to your wishes, can be regarded as acceptable.

As previous research has shown, the normalisation of abuse is sometimes further perpetuated when young people equate control to love, care and protection (Wood et al, 2010; Barter, 2009). When this was perpetuated by peers and parents, it can further legitimize, consolidate and reinforce the denial of IPVA. This means that IPVA should be put in the wider context in which culture of violence is embedded. As McCarry and Lombard (2016: 128) have noted: Challenging attitudes that condone violence both at the individual and community level is a key priority in its prevention'. 
Normalisation of gendered violence and abuse does not mean that every young woman blindly follows this model. Some young women and young men reject it outright and others negotiate the parameters of what is expected of them. Young people's accounts suggest that change at an individual level is possible where dominant gendered cultural features are challenged by peer cultures, family support, specialist services or learning over time. Identifying whether interventions address those factors that facilitate and constrain individuals' agency in the face of cultural violence could provide a means of ensuring the relevance of any programmes in this area (see Hellevik et al, 2015).

Progress towards challenging binary stereotypes of femininity and masculinity appears slow, even in the context of supportive family, peer and service environments, and this may reflect the dominance of cultural structures, indicateing that the process of challenging cultural norms and structural violence is complex. Those young women who did not conform to some of the cultural expectations they encountered also continued to repeat some heteronormative patterns, such as feeling responsible for pleasing and placating partners. Our data confirmed that heteronormative models of femininity and masculinity that are inscribed in cultural scripts of national, school, peer and familial practices (cultural violence) are used to justify controlling behaviours, sexual pressure and coercion.

Aggression, controlling behaviour and sexual coercion can be framed by young people using narratives of romance and love but still impact upon young women's self-esteem. Any theoretically informed interventions (Ali et al 2011) seeking to reduce young people's perpetration and experience of IPVA should therefore draw on understandings of dominant masculinity and young people's competence as social actors. We have used Aghtaie's (2015) framework of cultural violence and Stark's (2007) work on universal masculinity to provide a useful starting point for understanding how young people's experience of pressure and control is underscored by dominant narratives of ideal manhood and womanhood, leaving 
some young women feeling that they should accept abuse even though they may suffer in the process. Digital technologies do provide new patriarchal platforms for extending the scope and regularity of monitoring and emotional abuse, but they also offer methods of resistance. Young people who experience IPVA, and some who perpetrate it, are showing the capacity to challenge cultures that promote and endorse male domination and heteronormative beliefs. In line with previous literature (Drauker and Martsloff, 2010), theorising young people's experience of IPVA therefore must also engage in understanding of how old and new forms of support and technologies can be mobilised to build opportunities for resistance.

\section{Funding}

The author(s) disclosed receipt of the following financial support for the research, authorship, and/or publication of this article: This research (ref no. JUST/2011/DAP/ AG/3330) was funded by the DAPHNE III Programme of the European Commission.

\section{References:}

Aghtaie, N. (2017) Rape within heterosexual intimate relationships in Iran: legal frameworks, cultural and structural violence, Families, Relationships and Societies, Vol 6, No 2, 167-183.

Aghtaie, N. (2016) Iranian Women's Perspectives on Violence against Women in Iran and the UK. Iranian Studies. Vol 9, No 4, 593-611.

Aghtaie, N. \& Gangoli. G (2015) Understanding Gender Based Violence in National and International Contexts. London: Routledge.

Aghtaie, N, 2015, Men as women's guardians: Domestic violence in Iran, in N Aghtaie and G Gangoli, eds, Understanding gender-based violence: National and international contexts, London: Routledge 
Ali, B., Swahn, M., \& Hamburger, M. (2011). Attitudes affecting physical dating violence perpetration and victimization: Findings from adolescents in a high-risk urban community. Violence and Victims, 26, 669-683.

Barter C, 2009. In the name of love: partner abuse and violence in teenage relationships. British Journal of Social Work 39: 211-233.

Barter C, McCarry M, Berridge D, Evans K, 2009. Partner Exploitation and Violence in Teenage Intimate Relationships. NSPCC: London.

Braun, V. and Clarke, V. (2006) Using thematic analysis in psychology. Qualitative Research in Psychology, 3 (2). pp. 77-101.

Burman B, Cartmel F, 2005. Young people's attitudes towards gendered violence. NHS Scotland: Edinburgh.

Charles N, Mackay F, 2013. Feminist politics and framing contests: Domestic violence policy in Scotland and Wales. Critical Social Policy 33(4): 593-615.

Connell R W, 1987. Gender and power. Sydney, Australia: Allen and Unwin.

Draucker, C. and Martsolf, D. 2010. Dating Violence. Journal of Child and Adolescent Psychiatric Nursing 23 (3):133-42

Eaton AA, Matamala A, 2014. The relationship between heteronormative beliefs and verbal sexual coercion in college students. Archives of Sexual Behavior, 43(7): 1443-1457.

European Institute for Gender Equality. (2013). Gender equality index report. Italy: European Institute for Gender Equality.

Fineran S, Bennett L, 1999. Gender and power issues of peer sexual harassment among teenagers. Journal of Interpersonal Violence 14:626-41. 
Foshee VA, Matthew RA, 2007. Adolescent dating abuse perpetration: A review of findings, methodological limitations, and suggestions for future research. In The Cambridge handbook of violent behavior and aggression. Flannery DJ, Vazsonyi AT, Waldman ID. Cambridge University Press: New York, 431-449.

Foshee VA, Benefield T, Suchindran C, Ennett ST, Bauman KE, Karriker-Jaffe KJ, Reyes HLM, Mathias J. 2009. The development of four types of adolescent dating abuse and selected demographic correlates. Journal of Research on Adolescence. 19(3):380-400.

Fox CL, Corr M, Gadd D, 2014. Young teenagers' experiences of domestic abuse. Journal of Youth Studies. 17(4): 510-526. DOI: 10.1080/13676261.2013.780125.

Galtung, J. (1990) Cultural violence, Journal of Peace Research, 27(3): 291-305.

Hellevik, P.,M., Överlien, C., Barter, C., Wood, M., Aghtaie, N., Larkins, C., \& Stanley, N. (2015) Traversing the generational gap: Young people's views on intervention and prevention of teenage intimate partner violence. In: Stanley, N. and Humphreys, C. (Eds.), Domestic Violence and Protecting Children: New Thinking and Approaches. London: Jessica Kingsley.

Leadbeater B, Banister E, Ellis W, Yeung R, 2008. Journal of Youth and Adolescence. 37(3): $359-372$.

Livingstone, S., Haddon, L., Görzig, A., \& Olafsson, K. (2011). Risks and safety on the internet: The perspective of European children. Full findings. London, England: London School of Economics/EU Kids Online. Maas, D.; Fleming, B.; Herrenkohl, I.; Catalano, F. (2010)Childhood Predictors of Teen Dating Violence Victimization. Violence and Victims, Volume 25, Number 2, 2010, pp. 131149(19) 
Lombard, N. (2014) Because they're a couple she should do what he says': Young People's justifications of violence: heterosexuality, gender and adulthood, Journal of Gender Studies, 25 (3): 241-253.

McCarry, M. \& Lombard, N. (2016)same old story? children and young people's continued normalisation of men's violence against women, Feminist Review, 112(1): 128-143.

Messerschmidt J W,2012. Engendering Gendered Knowledge: Assessing the Academic Appropriation of Hegemonic Masculinity, Men and Masculinities, 15, 1.

Nocentini A, Calmaestra J, Schultze-Krumblholz A, Scheithauer H, Ortega R, Menesini E, 2010. Cyberbullying: labels, behaviours and definition in three European countries.

Australian Journal of Guidance and Counselling. 20(2): 129-142.

Powell A, 2007. Sexual pressure and young people's negotiation of consent. ACSSA Newsletter, No 14 June.

Ritchie J, Lewis J. Elam G, 2003. Designing and selecting samples. In

J. Ritchie \& J. Lewis (eds.) Qualitative Research Practice. London: Sage Publications.

Schnurr, M.P.; Lohman, B. J.; Kaura, S. A. Violence and Victims, Volume 25, Number 1, 2010, pp. 84-100(17)

Spencer, G. ; Maxwell, C. ; Aggleton, P. (2008)What does 'empowerment' mean in schoolbased sex and relationships education?, Sex Education, Volume 8, Issue 3, 345-356.

Stark E, 2007. Coercive Control: How Men Entrap Women in Personal Life. University Press: New York.

Tolman D, Spencer R, Rosen-Reynosa M, Porche M, 2003. Sowing the seeds of violence in heterosexual relationships: Early adolescents narrate compulsory heterosexuality. Journal of Social Issues 59:159-78. 
West C, \&Zimerman H, 1987. Doing Gender. Gender and Society. 1(2): 125-151.

Wood JT, 2001. The Normalization of Violence in Heterosexual Romantic Relationships:

Women's Narratives of Love and Violence. Journal of Social and Personal Relationships. 18(2): 239-261.

Wood, M \& Barter, C, 2015, 'Hope and Fears: Teenage Mothers' Experiences of Intimate Partner Violence'. Children and Society, vol29., pp. 558-568

Wyness, M. (2014) Children, family and the State : revisiting public and private realms.

Sociology - The Journal of the British Sociological Association, Volume 48 (Number 1). pp. $59-74$.

iThe terminology 'dating violence' is commonly employed in the US literature. However, this term does not transfer easily to other contexts (Barter, 2009). This is because, in the UK, adolescents hardly ever use the term 'dating' in their everyday conversation. 